\title{
PENGARUH LINGKUNGAN KERJA DAN MOTIVASI KERJA TERHADAP PRODUKTIVITAS KERJA KARYAWAN JASA KONTRUKSI DI PT KADI INTERNATIONAL
}

\author{
Ahmad Sobandi \\ Program Studi Manajemen, FBIS UBP Karawang \\ mn15.ahmadsobandi@mhs.ubpkarawang.ac.id \\ Uus Mohammad Darul Fadli \\ Program Studi Manajemen, FBIS UBP Karawang \\ uus.fadli@ubpkarawang.ac.id \\ Enjang Suherman \\ Program Studi Manajemen, FBIS UBP Karawang \\ enjangsuherman@ubpkarawang.ac.id
}

\begin{abstract}
ABSTRAK
Penelitian ini bertujuan untuk menjelaskan lingkungan kerja, motivasi kerja, produktivitas kerja karyawan dan hubungan dari ketiga variabel tersebut di PT. Kadi International. Pendekatan penelitian menggunakan deskriptif kuantitatif. Data dikumpulkan dengan kuisioner kepada sampel dari 60 orang karyawan perusahaan yang bersedia dan diijinkan perusahaaan untuk diteliti, selanjutnya data dianalisis mengunakan analisis frekuensi, analisis rentang skala dan analysis jalur (path analysis). Hasil penelitian menunjukkan bahwa perusahaan memiliki lingkungan kerja dengan modus yang baik, motivasi kerja karyawan yang tinggi serta memiliki produktivitas karyawan yang tinggi pula. Korelasi lingkungan kerja dan motivasi kerja karyawan sebesar 0,357 dan signifikan. Secara parsial lingkungan kerja berpengaruh positif terhadap produktivitas sebesar $4 \%$ (signifikan), sedangkan motivasi kerja berpengaruh positif terhadap produktivitas kerja karyawan sebesar 44\% (signifikan). Secara simultan lingkungan kerja dan motivasi kerja berpengaruh positif sebesar $58,1 \%$ terhadap produktivitas kerja karyawan di perusahaan tersebut dan sangat signifikan.
\end{abstract}

Kata Kunci: lingkungan kerja, motivasi kerja, produktivitas kerja 


\begin{abstract}
This study aims to explain the work environment, work motivation, employee work productivity and the relationship of the three variables at PT. Kadi International. The research approach uses quantitative descriptive. Data were collected by questionnaire to a sample of 60 company employees taken proportionally, then the data were analyzed by frequency scale analysis and path analysis. The results showed that the company has a good work environment, high employee motivation and high employee productivity. The correlation of work environment and employee motivation is 0.357 and significant. Partially the work environment has a positive effect on productivity by .4\% (significant), while work motivation has a positive effect on employee work productivity of $44 \%$ (significant),. Simultaneously the work environment and work motivation had a positive effect of $58,1 \%$ on the work productivity of employees in the company and were very significant.
\end{abstract}

Keywords: work environment, work motivation, work productivity

\title{
PENDAHULUAN
}

PT. Kadi International adalah sebuah perusahaan kontraktor umum yang bergerak di bidang jasa kontruksi, pembangunan gedung dan pembangunan prasarana sipil. Perusahaan telah turut serta dalam proyek pembangunan jalan tol Jakarta Cikampek, Simpang Cawang, Tunjungan Plaza Surabaya, Landmark Tower Jakarta dan proyek-proyek prestisius lainnya yang dibangun di luar Indonesia. Keberhasilan PT. Kadi Internasional tidak lepas dari peran dari karyawan sebagai Sumber Daya Manusia (SDM) sebagai bagian dari sumber daya strategis perusahaan. Pengembangan SDM yang terencana dan berkelanjutan merupakan kebutuhan yang mutlak terutama untuk masa depan organisasi sumber daya manusia merupakan hal yang sangat penting dalam suatu organisasi tentunya dalam perkembangan organisasi dan juga demi keberlangsungan hidup organisasi itu sendiri (Triatusti, 2018).

Produktivitas mempunyai arti ukuran yang relatif nilai atau ukuran yang ditampilkan oleh daya produksi, yaitu sebagai campuran dari produksi dan aktivitas, sebagai ukuran yaitu seberapa baik kita menggunakan sumber daya dalam mencapai hasil yang diinginkan (Ravianto dalam Edy Sutrisno 2016:99).

Pentingnya produktivitas dalam meningkatkan kesehjatraaan telah disadari secara universal tidak ada jenis kegiatan manusia yang tidak mendapatkan keuntungan dari produktivitas yang ditingkatkan sebagai kekuatan untuk 
menghasilkan lebih banyak barang maupun jasa, peningkatan produktivitas juga menghasilkan peningkatan langsung pada standar hidup berada di bawah kondisi distribusi yang sama dan perolehan produktivitas yang sesuai dengan masukan tenaga kerja (Serdamayanti, 2011:195)

Produktivitas dalam suatu perusahaan merupakan tolak ukur tentang berhasilnya suatu perusahaan dalamm menjalankan aktivitas nya, dalam hal ini faktor-faktor yang mempengaruhi produktivitas harus sangat diperhatikan oleh pimpinan perusahaan, agar dalam menjalankan aktivitas perusahaan dapat berjalan dengan lancar. (Nuraini, dkk., 2015) Banyak hal yang mempengaruhi terciptanya iklim organisasi atau lingkungan kerja adanya kesempatan untuk promosi sesuai dengan prestasinya dan juga adanya suatu penghargaan dalam kekompakan dalam suatu pekerjaan. lingkungan kerja juga dipengaruhi oleh kegiatan organisasi yang dilakukan secra sadar ataupun tidak sadar dapat mempengaruhi tingkah laku karyawan tersebut. (Zainul hidayat,\& muchamad taufiq, 2012)

Produktivitas adalah hubungan antara hasil nyata ataupun fisik (barang dan jasa) dan masukan yang sebenarnya. Saguan dalam Sedarmayanti, (2017:341) merupakan kemampuan untuk menghasilkan barang dan jasa yang biasanya dihitung per jam, per bualan, per mesin dan per faktor produksi lainnya.Komarudin dalam Sedarmayanti ( 2017:341). Peningkatan suatu produktivitas dapat dilakukan dengan beberapa cara salah satunya adalah dengan memperbaiki lingkungan kerja dengan lingkungan kerja yang kondusif dan nyaman dengan kondisi tersebut akan meningkatkan produktivitas karyawan tersebut dan juga dengan kondisi lingkungan tersebut maka akan meningkatkan semangat kerja karyawan dan akan memotivasi karyawan untuk mencapai tujuan perusahaan (Sinaga, 2016)

Menurut Diana Khairani Sofyan (2013: 20) lingkungan kerja adalah "segala sesuatu yang berada di sekitar karyawan yang mempengaruhi dirinya dalam menjalankan dan menyelesaikan tugas-tugas yang diberikan kepadanya dalam suatu wilayah, Kemudian. Sedarmayanti (2011:26) menjelaskan bahwa secara garis besar jenis lingkungan kerja terbagi menjadi 2 yaitu (1) Lingkungan kerja fisik, yakni semua keadaan yang berbentuk fisik yang terdapat di sekitar tempat kerja yang dapat mempengaruhi karyawan baik secara langsung maupun tidak langsung; dan (2) Lingkungan kerja Non fisik, yakni 1 semua keadaan yang terjadi yang 
berkaitan dengan hubungan kerja baik hubungan dengan atasan maupun hubungan sesama rekan kerja, ataupun hubungan dengan bawahan.Menurut Nela R., dkk (2014) Faktor pendorong seseorang dalam untuk melakukan suatu aktivitas pada umumnya adalah kebutuhan serta keinginan orang itu sendiri, jika seseorang itu membutuhkan atau menginginkan sesuatu maka dia akan terdorong untuk melakukan aktivitas untuk mendapatkan apa yang dibutuhkannya (Edy Sutrisno 2010:146).

Motivasi adalah kekuatan yang mendorong seseorang untuk melakukan suatu tindakan atau tidak yang pada hakikatnya ada secara internal dan ekternal positif atau negatif untuk mengarahkan sangat bergantung pada ketangguhan pemimpin Serdamayanti (2017:154), sebagai pendorong seseorang untuk melakukan suatu aktivitas tertentu, oleh karena itu motivasi sering kali diartikan pula sebagai faktor pendorong perilaku seseorang. Setiap aktivitas yang dilakukan oleh seseorang pasti memiliki suatu faktor yang mendorong aktivitas tersebut. Oleh karena itu,faktor pendorong dari seseorang untuk melakukan suatu aktivitas tertentu pada umumnya adalah kebutuhan serta keinginan orang tersebut" (Edy Sutrisno 2010:109).

Motivasi merupakan serangkaian sikap dan nilai-nilai yang mempengaruhi individu untuk mencapai hal yang spesifik sesuai denagan tujuan individu sikap danilai tersebut merupakan suatu yang tidak tampak yang memberi kekuatan untuk mendorong individu berprilaku dalam mencapai tujuan. Pada dasarnya motivasi dapat memacu pegawai untuk bekerja keras sehingga dapat dai mencapi tujuan mereka. (Serdamayanti 2017:162)

Terdapat beberapa hal yang mempengaruhi motivasi, sehingga motivasi karyawan tersebut menjadi meningkat yaitu gaji atau upah (reward), prestasi, afiliasi, kekuasaan atau karier, dengan adanya motivasi yang tinggi dapat mempengaruhi peningkatan produktivitas kerja, dalam suatu organisasi pemimpin unit kerja atau instansi memiliki kewajiban untuk selalu memotivasi karyawannya agar dapat bekerja meningkatkan kinerjanya, karena kerjasama dan saling memahami tugas dan fungsi dari setiap unit kerja sangat diperlukan. (Desi Rahmawati).

Menurut Nuraini, dkk (2015) lingkungan kerja dan motivasi berpengaruh secara simultan terhadap produktivitas kerja karyawan. Dengan demikian untuk 
meningkatkan produktivitas kerja karyawan, maka manajemen perlu memperhatikan penerapan motivasi dan lingkungan kerja di perusahaan tersebut.

Penelitian ini bertujuan untuk mendeskripsikan kondisi lingkungan kerja, motivasi kerja, produktivitas karyawan serta hubungan dari ketiga variabel yang diteliti di PT. Kadi International.

\section{METODE PENELITIAN}

Penelitian ini menggunakan pendekatan kuantitatif. Jumlah responden sebanyak 60 orang karyawan, sesuai dengan jumlah yang bersedia dan diperbolehkan untuk dijadikan sample penelitian oleh HRD PT. Kadi International. Data dikumpulkan menggunakan kuesioner yang sudah dibuat secara terstruktur Selanjutnya data dianalisis mengunakan analisis rentang skala, analisis distribusi dan analisis jalur untuk menjelaskan kondisi eksisting dan hubungan antar variable setelah terlebih dahulu data ditransformasi ke data interval melalui MSI.

\section{ANALISIS DAN PEMBAHASAN}

Kondisi eksisting perusahaan dijelaskan melalui modus penyebaran data, yakni lingkungan kerja dalam kondisi yang baik, motivasi karyawan berada pada modus yang tinggi, begitu pula dengan produktivitas kerja karyawan juga memiliki modus yang tinggi (Tabel 1).

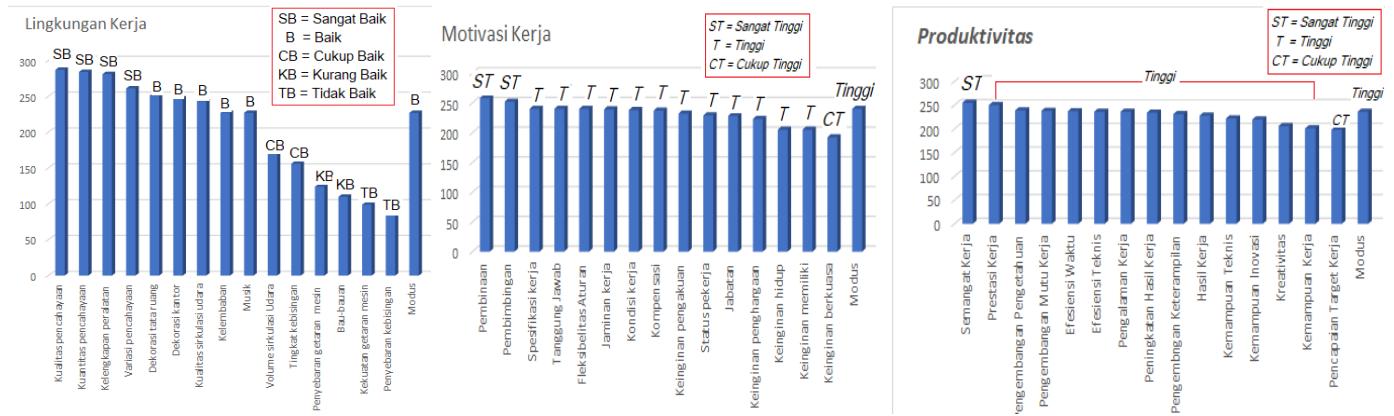

Tabel 1 : Frekuensi Lingkungan Kerja, Motivasi dan Produktivitas Kerja Karyawan

Dari tabel 1 diketahui bahwa lingkungan kerja yang masih perlu diperhatikan adalah penurunan tingkat kebisingan dan getaran mesin. Dari sisi motovasi karyawan nampaknya sudah baik, sedangkan untuk meningkatkan produktivitas yang perlu diperhatikan adalah upaya untuk mencapai target kerja sesuai yang diharapkan perusahaan. 
Hubungan antar variable yang diteliti menunjukkan bahwa lingkungan kerja berkorelasi secara signifikan dengan motivasi karyawan $(r=0,357)$ artinya peningkatan kondisi lingkungan kerja dapat meningkatkan motivasi kerja atau sebalikya. Secara parsial lingkungan kerja berpengaruh positif signifikan untuk meningkatkan produtivitas karyawan dengan koefisien jalur sebesar 0,205 sedangkan motivasi secara parsial mempengaruhi produktivitas kerja karyawan positif sangat signifikan dengan koefisien jalur $(\beta=0,664)$. Hal ini menunjukkan bahwa motivasi karyawan memiliki peran yang lebih besar dibandingkan dengan lingkungan kerja dalam meningkatkan produktivitas kerja karyawan di perusahaan tersebut.
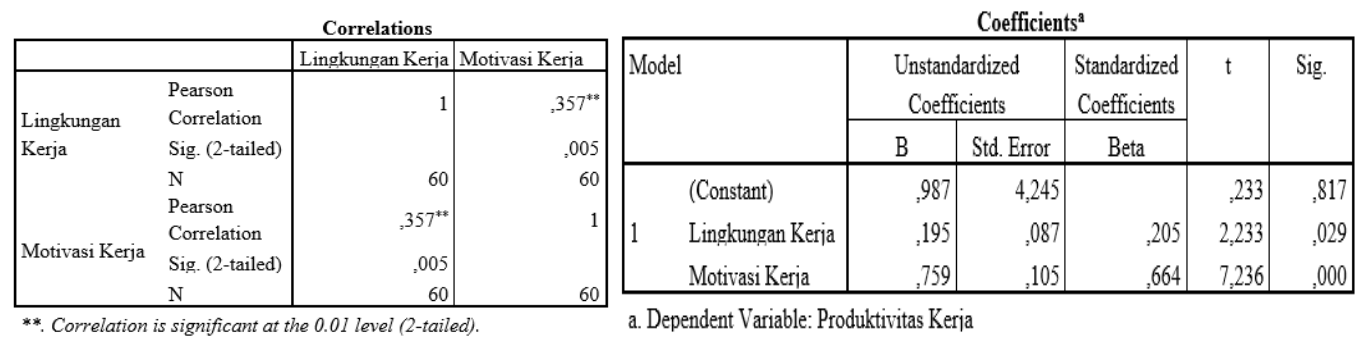

\begin{tabular}{|c|c|c|c|c|}
\hline Model & $\mathrm{R}$ & $\begin{array}{c}\mathrm{R} \\
\text { Square }\end{array}$ & $\begin{array}{c}\text { Adjusted R } \\
\text { Square }\end{array}$ & $\begin{array}{c}\text { Std. Error of } \\
\text { the Estimate }\end{array}$ \\
\hline 1 &, $762^{\mathrm{a}}$ &, 581 &, 566 & 4,745 \\
\hline
\end{tabular}

\begin{tabular}{|l|c|r|r|c|c|}
\hline Model & $\begin{array}{c}\text { Sum of } \\
\text { Squares }\end{array}$ & df & $\begin{array}{c}\text { Mean } \\
\text { Square }\end{array}$ & F & Sig. \\
\hline Regression & 1777,203 & 2 & 888,601 & 39,474 &, $000^{\mathrm{b}}$ \\
1 Residual & 1283,132 & 57 & 22,511 & & \\
\multicolumn{7}{|c|}{ Total } & 3060,335 & 59 & & & \\
\hline
\end{tabular}
a. Dependent Variable: Produktivitas Kerja
b. Predictors: (Constant), Motivasi Kerja, Lingkungan Kerja

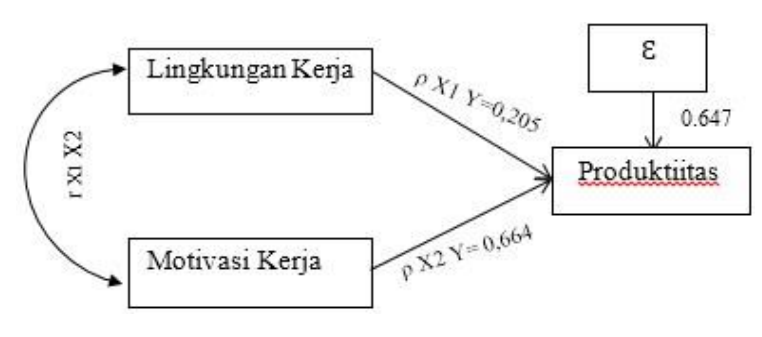

Tabel 2 : Hubungan Lingkungan Kerja, Motivasi dan Produktivitas Karyawan

Secara simultan Lingkungan kerja dan motivasi berpengaruh secara signifikan terhadap produksivitas kerja dengan koefisien determinasi sebesar $76,20 \%$ dan memenuhi formulasi hubungan jalur $\mathrm{Y}=0,205 \mathrm{X}_{1}+0,664 \mathrm{X}_{2}+0,647 \varepsilon$ ( $\mathrm{Y}=$ produktivitas kerja; $\mathrm{X}_{1}=$ lingkungan kerja; dan $\mathrm{X}_{2}=$ motivasi karyawan).

Hasil penelitian ini mendukung hasil penelitian sebelumnya yang dilakukan oleh Chabib Bahari dan Agung Wahyudi (2014) di bagian Phonska IV PT. Petrokimia Gresik, dan hasil penelitian Nuraeni, dkk (2015) pada karyawan PTPN Kecamatan Tapung bahwa lingkungan kerja dan motivasi berpengaruh positif dan signifikan dalam meningkatkan produktivitas kerja karyawan. 


\section{KESIMPULAN}

1. Kondisi eksisting perusahan pada kondisi lingkungan kerja yang baik, motivasi karyawan tinggi dan produktivitas kerja karyawan juga dalam kondisi yang tinggi, namun demikian perusahaan perlu menurunkan tingkat kebisingan dan getaran mesin agar dapat lebih meningkatkan kualitas lingkungan kerja, motivasi dan prduktivitas kerja karyawan.

2. Motavasi secara siginifikan memiliki pengaruh yang lebih besar dibandingkan dengan lingkungan kerja dalam meningkatkan produsktivitas kerja karyawan. Lingkngan kerja, dan motivasi secara simultan berpengaruh positif dan sangat signifikan dalam meningkatkan produktivitas kerja karyawan.

\section{DAFTA PUSTAKA}

Chabib B, dan Agung Wahyudi (2014) Pengaruh Motivasi Kerja Dan Lingkungan Kerja Terhadap Produktivitaskerja Karyawan Dibagian Phonska IV PT Petrokimia Gersik. Jurnal Fakultas Ekonomi 03(1).

Nela Rahmawanti, Pima,Bambang Swasto dan Arik Prasetya (2014) Pengaruh Lingkungan Kerja Terhadap Kinerja Karyawan (Studi pada Karyawan Kantor Pelayanan Pajak Pratama Malang Utara). Jurnal Administrasi Bisnis $(J A B) \mid 8(2)$.

Nuraini, Indrianti, dan Marzolina, (2015), Pengaruh lingkungan kaerja dan motivasi terhadap produktivitas kerja karyawan pada PT.Perkebunan Nusantara V Cabang Kebun Inti kecamatan Tapung Kabupaten kampur.Jurnal JOM FEKON 2 (1).

Rahmawati, Desi (2013) Pengaruh Motivasi Terhadap Produktivitas Kerja Karyawan PR Fajar Berlian Tulungagung. Jurnal Universitas Tulungagung BONOROWO 1 (1).

Sedarmayanti.2017.Perencanaan dan Pengembangan Sumber Daya Manusia.Bandung:RefikaAditama

Serdamayanti.2011. Tata kerja dan produktivitas kerja: suatau tinjauan dari aspek ergonomi atau kaitan antara manusia dengan lingkungan kerjanya. Bandung Mandiri Maju. 
Sinaga Swandono.(2016) Pengaruh Lingkungan Kerja Terhadap Produktivitas Kerja Karyawan(Bagian Produksi Minyak Kelapa Sawit Pt.Mitra Unggul Pusaka Segati Pelalawan Riau). Jom Fisip 3 (2).

Sofyan, Diana Khairani. 2013. Pengaruh Lingkungan Kerja terhadap Kinerja Pegawai Bappeda. Malikussaleh. Industrial Engineering Jurnal, 2, 1, 20.

Sutrisno Edy.2010 Manajemen Sumber Daya Manusia.Cetakan Kedua. Jakarta Kencana Prenamedia Group.

Sutrisno Edy.2016. Manajemen Sumber Daya Manusia.Jakarta Kencana Prenamedia Group.

Triatusti Dinie Anisa.2018. Pengaruh Lingkungan Kerja, Kopetensi Dan Iklim Organisasi Terhadap Kinerja Pegawai Pada Bank BJB Cabang Tasikmalaya. Journal Of Management Reivew 2(1)

Zainul Hidayat \& Muchamad Taufiq (2012) Pengaruh Lingkungan Kerja dan Disiplin Kerja serta Motivasi Kerja Terhadap Kinerj Karyawan Perusahaan Daerah Air Minum(PDAM) Kabupaten Lampung. Jurnal WIGA 2 (1). 